\title{
Purine Turnover Metabolites and Selected Antioxidants in Blood of Goats during the Periparturient Period
}

\author{
Ewa Skotnicka, Irena Baranowska-Bosiacka ${ }^{1}$, Wioleta Dudzińska, Maria Suska \\ Department of Physiology, Faculty of Life Sciences, University of Szczecin, Poland, \\ ${ }^{1}$ Department of Biochemistry and Medical Chemistry, \\ Pomeranian Medical University, Szczecin, Poland
}

Received February 23, 2009

Accepted September 21, 2010

\begin{abstract}
The aim of this study was to examine the relationships between the erythrocyte concentrations of ATP, ADP, AMP, NAD ${ }^{+}, \mathrm{NADP}^{+}$and adenylate energy charge (AEC) and their metabolites: inosine (Ino), hypoxanthine (Hyp), uric acid (UA), selected blood antioxidants: superoxide dismutase (SOD), glutathione reductase (GR) of goats during the periparturient period.

The study was conducted on 12 clinically healthy pregnant goats (Capra hircus) - 75\% genotype of the Polish noble white aged between 2-3 years. Blood was taken from the external jugular vein early in the morning before feeding and obtained twice (4 weeks and 1 week) before delivery and twice ( 2 and 3 weeks) after delivery.

The ATP concentration did not change significantly. One week before delivery ADP, AMP and Ino concentrations were significantly higher and AEC value significantly lower compared to values in the third week after delivery $(p \leq 0.02, p \leq 0.05, p \leq 0.03$ and $p \leq 0.01$, respectively). One week before and two weeks after delivery we observed a significant increase in SOD and GR activities and an increase in $\mathrm{NAD}^{+}$and $\mathrm{NADP}^{+}$concentrations but a significant decrease in Hyp and UA concentrations. Constant ATP concentration and the changes in the dynamics and tendency of Hyp and UA concentrations show that in the periparturient period in goats, purine metabolism undergoes adaptive changes. The balance between resynthetic processes and adenine nucleotide degradation is retained in order to level the oxygen and energy lacks. The results of our study show that the maintenance of prooxidative homeostasis in goats of peripartal period depends mainly on enzymatic mechanisms.
\end{abstract}

Adenine nucleotide, oxypurines, oxidative stress, peripartal period, ruminants, HPLC

Pregnancy is a physiological state in the mother's organism which provides the embryo with optimum conditions for its development. In the periparturient period many organs and regulation systems are highly mobilized (Skotnicka 2003; Skotnicka 2005). Pregnant females exhibit numerous haemodynamic changes: an increase in stroke volume, decrease in the resistance of peripheral vessels, and the growth of the vascular placenta. An increase in oxygen and energy demand can be also observed (Makker et al. 2006). Delivery and lactation demand enormous physical effort which in extreme cases may lead to exhaustion and even to homeostatic disorders (Gitto et al. 2002).

In the periparturient period the female is particularly exposed to disturbance of energy balance as well as disturbance of balance between the production of reactive oxygen species and the optimization of mechanisms protecting against the results of oxidative stress (Górecka et al.2002; Toescu et al. 2002; Wender-Ożegowska et al. 2004; Upadhyaya et al. 2005, Erisir et al. 2009).

While the first pregnancy stage of mammals is characterized by intensification of anabolic changes, the second stage, especially the periparturient period, is characterised by intensification of catabolic processes (such as the increase of insulin resistance of cells, the increase of placenta hormonal activity, the increase of lipids, fat acids, glucose and amino acids degradation). Catabolic processes increase especially in conditions of hypoxia manifested by disturbance of adenine metabolism and generation of reactive

Address for correspondence:

Ewa Skotnicka, PhD

Department of Physiology, Institute of Life Sciences

University of Szczecin

Felczaka 3C, st

71-412 Szczecin, Poland
Phone: +4891 4441597

Fax: +4891 4441599

E-mail: ewaskot@univ.szczecin.pl

http://www.vfu.cz/acta-vet/actavet.htm 
oxygen species (ROS) with the use of xanthine oxidoreductase, the substrates of which are hypoxanthine and xanthine accumulated in tissues and created during the intensive ATP catabolism (Bontemps et al. 1986; Tavazzi et al. 2000). Moreover, ROS may react with cellular macromolecules and lead to functional disorders (Szelachowska et al. 2002). Radicals participate in the peroxidation of lipids, membrane unsaturated fatty acids and lead to degradation of cellular proteins. They can also disturb the processes of DNA replication and transcription through their influence on purine and pyrimidine alkalies and nucleic acid deoxyriboses (Sies 1997; Halliwell and Gutteridge 1999; Dröge 2002). The consequences of oxidative stress vary and have been widely discussed by many authors: lipid peroxidation, degradation of proteins, DNA impairment, and also the intensive catabolism of adenine nucleotides, a decrease in NADH synthesis, a decrease in the intracellular ATP concentration due to a decrease in NADH supply and inhibition of glycolysis (a decrease in glyceraldehyde-3-phosphate dehydrogenase activity, EC 1.2.1.12), an increase in cellular ATP consumption (ATP-dependent transport of glutathione disulfide: GSSG from cells, an increase in the activity of ATP-dependent proteases), an increase in the permeability of cell membranes and a decrease in the concentration of enzymatic and non-enzymatic antioxidants (Sies 1997; Dröge 2002).

The reactions of cellular oxygenation are controlled by enzymatic and non-enzymatic mechanisms (Szelachowska et al. 2002). Enzymatic antioxidants, preventing against ROS reactions include superoxide dismutase (SOD), glutathione reductase (GR), glutathione peroxidase (GPx) and catalase (CAT) and non-enzymatic like glutathione (GSH), ascorbate, tocopherols, retinoids and uric acid (Sies 1997; Halliwell and Gutteridge 1999; Dröge 2002). SOD (EC 1.15.1.1) catalyzes the dismutation of superoxide anion radical to hydrogen peroxide. GR (EC 1.6.4.2) is responsible for the regeneration of reduced glutathione, and its activity influences glutathione peroxidase that catalyzes (with the participation of glutathione) a degradation of hydrogen peroxide and organic peroxides:

$\mathrm{GSSG}+\mathrm{NADPH}+\mathrm{H}^{+} \rightarrow 2 \mathrm{GSH}+\mathrm{NADP}^{+}$.

During physiological pregnancy in women intracellular concentration of high energy nucleotides (ATP, ADP) decreases, of about 11\% (ATP) and about 13\% (ADP) in relation to the values observed in healthy nonpregnant women (Wójcicka et al. 1977). There is, however, an increase of purine turnover metabolites content, especially of inosine (Ino), hypoxanthine (Hyp) and uric acid (UA). An increase of $\mathrm{NADP}^{+}$and 2,3-BPG concentrations and integral amount of phosphorates has also been observed (Wójcicka et al. 1977). The disrupted adenine metabolites and disrupted balance between the speed of ROS production in a cell and their degradation accompanying hypoxia during the periparturient period may lead to different complications such as preeclampsia, abortion, premature birth and hypertension (Arikan et al. 2001; Bracci et al. 2002; Wender-Ożegowska et al. 2004; Bainbridge and Roberts 2008).

The number of scientific studies available on catabolism of high energy purines and the accompanying prooxidant-antioxidant processes in the periparturient period of small ruminants is limited.

The aim of this study was to examine the relationships between erythrocyte concentrations of ATP, ADP, AMP, $\mathrm{NAD}^{+}, \mathrm{NADP}^{+}$and adenylate energy charge (AEC), purine turnover metabolites and hypoxia indicators: inosine (Ino), hypoxanthine (Hyp), selected blood antioxidants: superoxide dismutase (SOD), glutathione reductase (GR) and uric acid (UA) of goats during the periparturient period.

\section{Materials and Methods}

Goats

The research was carried out during spring on milk-goats living on an individual farm in standardized conditions. The research was conducted during the periparturient period on 12 clinically healthy pregnant goats 
(Capra hircus) - 75\% genotype of the Polish noble white aged between 2-3 years and weighing $45-55 \mathrm{~kg}$. The deliveries were physiological and with no complications, with all females bearing single lambs.

Goats were housed in boxes on rye straw bedding and fed in compliance with nutritional norms for their physiological state: barley - bruised grain, $600 \mathrm{~g} /$ day, beet - dry beet pulp, 400g/day. Salt-licks $(94 \% \mathrm{NaCl})$ enriched with minerals (in ppm: $\mathrm{Co}-30, \mathrm{Cu}-150, \mathrm{Zn}-1300, \mathrm{I}-60, \mathrm{Mn}-1400, \mathrm{Mg}-18000$, Se -25 ) as well as water and good quality grass hay were offered ad libitum. Representative feed staff samples (hay, rye straws, bruised grain and beet pulp) were sent to a local agricultural laboratory for analysis of $\mathrm{Zn}, \mathrm{Cu}, \mathrm{Mn}$ concentrations (the hydride generation atomic absorption spectrometry was used).

Whole blood per heparinized test tube (250 IU heparine from Polfa, Poland) was taken from the external jugular vein early in the morning before feeding. Blood was obtained twice before delivery ( 4 and 1 weeks before delivery) and twice after delivery ( 2 and 3 weeks after). The goats did not show any sign of particular stress during blood sampling. The blood was delivered to the laboratory in ice flasks and immediately analyzed. All studies were approved by the Local Ethics Committee.

HPLC separation of purine

Concentrations of ATP, ADP, AMP, NAD ${ }^{+}, \mathrm{NADP}^{+}$, inosine, hypoxanthine, uric acid were measured by the HPLC method of Smolenski et al. [1990].

Chemicals: Purines used as chromatographic standards were obtained from Sigma-Aldrich USA. HPLC grade acetonitrile was obtained from Merck, USA. HPLC grade potassium dihydrogen orthophosphate, potassium chloride and tripotassium orthophosphate were obtained from Fluka Chemie GmbH, USA. HPLC grade water was prepared using a Milli-Q (Millipore purification system). All HPLC solvents were filtered through $0.22 \mu \mathrm{m}$ nylon filters (Supelco USA) before use.

Instrumentation: For the HPLC analysis the Hewlett Packard chromatographic system was used. The HP series 1100 chromatographic system consisted of a quaternary pump system with a degasser and a continuous seal wash option (G1311A), a variable-wavelength detector (G1314) and a thermostatted column compartment (G1316A). The analytical column $(100 \times 4.6 \mathrm{~mm}$ LC) was packed with $18.3 \mu \mathrm{m}$ Hypersil BDS-C (Hewlett Packard USA). Samples were introduced using a Rheodyne 7725 injection valve equipped with a $20 \mu \mathrm{m}$ loop. Sample peaks were integrated and quantified using an HPLC chromatography data system operating on Chemstation Software for Windows 98 (Hewlett Packard).

HPLC separation of purine: The samples of whole blood $(500 \mu \mathrm{l})$ were deproteinized with $500 \mu \mathrm{l}$ of $1.3 \mathrm{M}$ perchloric acid in $1.5 \mathrm{ml}$ Eppendorf tubes. Extract mixtures were centrifuged $\left(16,000 \mathrm{~g}\right.$ for $10 \mathrm{~min}$, at $\left.4{ }^{\circ} \mathrm{C}\right)$. The supernatant (600 Jl1) was neutralized with approximately $60-90 \mu \mathrm{l}$ of $3 \mathrm{M}$ potassium orthophosphate solution ( $\mathrm{pH}$ range of the sample at 6.3). The neutralized extract was centrifuged again and filtered through a nylon filter of $0.22 \mu \mathrm{m}$. The obtained clear filtrate was used directly for the HPLC assay or stored at $-80{ }^{\circ} \mathrm{C}$.

Chromatographic conditions: Sample aliquots (extract filtrate) $(100 \mu \mathrm{l})$ were injected into the chromatograph column and the nucleotides were separated using a linear phosphate buffer gradient system at the flow rate of $0.666 \mathrm{ml} / \mathrm{min}$ (buffer A: $150 \mathrm{mM} \mathrm{KH} \mathrm{mO}_{2}, 150 \mathrm{mM} \mathrm{KCI}$ adjusted to $\mathrm{pH} 6.0$ with $\mathrm{K}_{2} \mathrm{HPO}_{4}$; buffer B: $15 \% \mathrm{v} / \mathrm{v}$ solution of acetonitrile in buffer A). Peaks were detected by absorption measurements at $254 \mathrm{~nm}$. The composition of the mobile phase was controlled by a low-pressure gradient mixing device. The cycle time was 12.8 min between injections. The analytical column was maintained at constant temperature of $20.5^{\circ} \mathrm{C}$.

The ATP, ADP, AMP NAD ${ }^{+}, \mathrm{NADP}^{+}$concentrations obtained in the blood were calculated according to factors given in the assay method (Smolenski et al. 1990) and expressed as $\mu \mathrm{M}$ of RBC. The concentrations of inosine, hypoxanthine, uric acid expressed as $\mu \mathrm{M}$ in the whole blood. The adenylate energy charge (AEC) were calculated according to the formulas: $\mathrm{AEC}=(\mathrm{ATP}+0.5 \mathrm{ADP}) /(\mathrm{ATP}+\mathrm{ADP}+\mathrm{AMP})$.

Haemolysates were used for SOD and GR analysis. Analyses were performed according to instructions given by the manufacturer of the Assay Kits used in this study (Bioxytech SOD-525 Assay and Bioxytech GR-340 Assay by OXIS Research, Portland, OR, USA) with the use of UVIKON 922 spectrophotometer. The activities of erythrocyte SOD and GR enzymes were corrected for potential changes in the blood HB concentration by expressing as units of activity $(\mathrm{U})$ per gram of $\mathrm{Hb}(\mathrm{U} / \mathrm{g} \mathrm{Hb})$.

Statistical analysis

Statistical analysis was conducted using v.6.1. of Statistica software. The mean values $(\bar{x})$ and standard deviations (SD) were found for each of the studied indicators. The distribution of results for individual variables was obtained with the Shapiro-Wilk W test. To assess the differences between the studied groups, non-parametric Kruskal-Walis Anova and U Mann-Whitney tests were used. The Pearson's correlation coefficient was determined in all the groups for the concentrations of all the metabolites.

\section{Results}

Statistical analysis of ATP concentration in blood of the examined goats during the periparturient period did not show any significant differences (Table 1). Significant differences were found in ADP and AMP concentrations. ADP concentration was the highest in the goats' erythrocytes one week before delivery, and the lowest in the third week after delivery $(p \leq 0.02)$. Changes in AMP concentration were similar to those in 
ADP: in the $1^{\text {st }}$ week before delivery the concentration of nucleotides was at its highest and differed significantly with the remaining measuring points (Table 1). In goats one week before delivery, a positive correlation $(p \leq 0.05)$ between ATP and ADP $(r=0.99)$ was found. AEC value in all the examined groups was approximately constant and ranged 0.82-0.86 (Table 1).

Table 1. Concentration of ATP, ADP, AMP, $\mathrm{NAD}^{+}, \mathrm{NADP}^{+}$in erythrocytes $(\mu \mathrm{M})$ and adenylate energy charge (AEC) of goats in the periparturient period.

\begin{tabular}{|c|c|c|c|c|c|c|}
\hline & & $\begin{array}{c}4 \text { weeks } \\
\text { before delivery } \\
\text { A }\end{array}$ & $\begin{array}{c}1 \text { week } \\
\text { before delivery } \\
\text { B }\end{array}$ & $\begin{array}{c}2 \text { weeks } \\
\text { after delivery } \\
\text { C }\end{array}$ & $\begin{array}{c}3 \text { weeks } \\
\text { after delivery } \\
\mathrm{D}\end{array}$ & Significance \\
\hline $\begin{array}{l}\text { ATP } \\
(\mu \mathrm{M})\end{array}$ & $\mathrm{x}$ & 688.34 & 704.47 & 692.44 & 673.21 & \\
\hline & $\pm \mathrm{SD}$ & 81.90 & 76.52 & 67.69 & 62.37 & \\
\hline $\begin{array}{l}\text { ADP } \\
(\mu \mathrm{M})\end{array}$ & $\mathrm{x}$ & 214.42 & 242.81 & 220.67 & 190.72 & $\mathrm{BD}(p \leq 0.02)$ \\
\hline & $\pm \mathrm{SD}$ & 41.00 & 36.91 & 36.26 & 21.22 & \\
\hline $\begin{array}{l}\text { AMP } \\
(\mu \mathrm{M})\end{array}$ & $\mathrm{x}$ & 40.87 & 66.79 & 39.47 & 41.29 & $\begin{array}{l}\mathrm{BA}(p \leq 0.03) \\
\mathrm{BC}(p \leq 0.03)\end{array}$ \\
\hline & $\pm \mathrm{SD}$ & 7.44 & 16.96 & 16.19 & 9.97 & $\mathrm{BD}(p \leq 0.05)$ \\
\hline $\begin{array}{l}\mathrm{NAD}^{+} \\
(\mu \mathrm{M})\end{array}$ & $\mathrm{x}$ & 112.62 & 138.20 & 135.28 & 85.17 & $\begin{array}{l}\mathrm{BD}(p \leq 0.01) \\
\mathrm{CD}(p \leq 0.03)\end{array}$ \\
\hline & $\pm \mathrm{SD}$ & 30.53 & 29.41 & 27.82 & 9.92 & \\
\hline $\begin{array}{l}\text { NADP+ } \\
(\mu \mathrm{M})\end{array}$ & $\mathrm{x}$ & 32.61 & 49.82 & 38.91 & 31.52 & $\begin{array}{l}\mathrm{BA}(p \leq 0.03) \\
\mathrm{BD}(p \leq 0.04)\end{array}$ \\
\hline & $\pm \mathrm{SD}$ & 10.32 & 27.90 & 10.46 & 11.82 & \\
\hline $\mathrm{AEC}$ & & & & & & $\mathrm{BD}(p \leq 0.02)$ \\
\hline & $x$ & 0.84 & 0.82 & 0.84 & 0.86 & \\
\hline & $\pm \mathrm{SD}$ & 0.01 & 0.007 & 0.02 & 0.01 & \\
\hline
\end{tabular}

$\bar{x}$ - mean; $\pm \mathrm{SD}$ - standard deviation

One week before delivery we observed an increase in $\mathrm{NAD}^{+}$concentration, maintaining a high level even in week 2 after delivery (Table 1). In week 3 after delivery $\mathrm{NAD}^{+}$ concentrations decreased significantly. $\mathrm{NADP}^{+}$concentration significantly increased one week before delivery and significantly decreased in weeks 2 and 3 after delivery decreased significantly (Table 1).

In this research, changes in concentrations of $\mathrm{NAD}^{+}, \mathrm{NADP}^{+}$, and $\mathrm{AMP}$ show the same tendency as changes in the activity of antioxidative enzymes, with an increase in concentrations one week before delivery. SOD has the highest activity in week 2 after delivery. The change at this point was significant compared to the remaining data. Two weeks before delivery an increasing tendency was observed. GR activity increased significantly 1 week before and 2 weeks after delivery compared to 4 weeks before delivery $(p \leq 0.01)$. In week 3 after delivery we observed a decrease in the activity of both the examined enzymes (Table 2). Positive correlation between SOD and GR activity $(p \leq 0.05)$ was found in goats only 4 weeks before delivery $(r=0.98)$.

Ino, Hyp and especially UA concentrations were high during the periparturient period, (especially in week 4 before delivery), and gradually decreased in week 2 after delivery (Table 3). The changes were significant (Ino $p \leq 0.05$; Hyp $p \leq 0.01$; UA $p \leq 0.007$ ). Ino concentration maintained low level even in week 3 after delivery $(p \leq 0.02$ compared to 4 weeks before delivery and $p \leq 0.03$ compared to 1 week before delivery). Hyp concentration in week 3 after delivery increased significantly compared to week 2 after delivery $(p \leq 0.02)$. 
Table 2. Superoxide dismutase (SOD) and glutathione reductase (GR) activity in erythrocytes (U/g Hb) of goats in the periparturient period.

\begin{tabular}{|c|c|c|c|c|c|c|}
\hline & & $\begin{array}{c}4 \text { weeks } \\
\text { before delivery } \\
\text { A } \\
\end{array}$ & $\begin{array}{c}1 \text { week } \\
\text { before delivery } \\
\text { B }\end{array}$ & $\begin{array}{c}2 \text { weeks } \\
\text { after delivery } \\
\mathrm{C}\end{array}$ & $\begin{array}{c}3 \text { weeks } \\
\text { after delivery } \\
\mathrm{D}\end{array}$ & Significance \\
\hline \multirow[t]{2}{*}{$\begin{array}{l}\text { SOD } \\
(\mathrm{U} / \mathrm{g} \mathrm{Hb})\end{array}$} & $\mathrm{x}$ & 81.17 & 89.23 & 110.92 & 67.16 & \multirow{2}{*}{$\begin{array}{l}\mathrm{AC}(p \leq 0.03) \\
\mathrm{BC}(p \leq 0.05) \\
\mathrm{DC}(p \leq 0.003)\end{array}$} \\
\hline & $\pm \mathrm{SD}$ & 26.29 & 24.13 & 26.16 & 22.63 & \\
\hline \multirow[t]{2}{*}{$\begin{array}{l}\text { GR } \\
(\mathrm{U} / \mathrm{g} \mathrm{Hb})\end{array}$} & $\mathrm{x}$ & 87.44 & 181.24 & 197.80 & 105.45 & \multirow[t]{2}{*}{$\begin{array}{l}\mathrm{AB}(p \leq 0.01) \\
\mathrm{AC}(p \leq 0.01)\end{array}$} \\
\hline & $\pm \mathrm{SD}$ & 36.51 & 46.89 & 35.06 & 34.25 & \\
\hline
\end{tabular}

$\bar{x}$ - mean; $\pm \mathrm{SD}$ - standard deviation

Table 3. Concentration of inosine (Ino), hypoxantine (Hyp) and uric acid (UA) in whole blood $(\mu \mathrm{M})$ of goats in periparturient period.

\begin{tabular}{|c|c|c|c|c|c|c|}
\hline & & $\begin{array}{c}4 \text { weeks } \\
\text { before delivery } \\
\text { A }\end{array}$ & $\begin{array}{c}1 \text { week } \\
\text { before delivery } \\
\text { B }\end{array}$ & $\begin{array}{c}2 \text { weeks } \\
\text { after delivery } \\
\text { C }\end{array}$ & $\begin{array}{c}3 \text { weeks } \\
\text { after delivery } \\
\text { D }\end{array}$ & Significance \\
\hline $\begin{array}{l}\text { Ino } \\
(\mu \mathrm{M})\end{array}$ & $\mathrm{x}$ & 13.13 & 13.83 & 9.23 & 9.13 & $\begin{array}{l}\mathrm{AC}(p \leq 0.05) \\
\mathrm{DA}(p<0.02)\end{array}$ \\
\hline & $\pm \mathrm{SD}$ & 3.26 & 5.15 & 4.97 & 3.04 & $\mathrm{DB}(p \leq 0.03)$ \\
\hline $\begin{array}{l}\text { Hyp } \\
(\mu \mathrm{M})\end{array}$ & $\mathrm{x}$ & 36.10 & 33.75 & 24.00 & 39.57 & $\begin{array}{l}\mathrm{AC}(p \leq 0.01) \\
\mathrm{DC}(p \leq 0.02)\end{array}$ \\
\hline & $\pm \mathrm{SD}$ & 1.12 & 10.56 & 7.47 & 12.76 & \\
\hline $\begin{array}{l}\text { UA } \\
(\mu \mathrm{M})\end{array}$ & $\mathrm{x}$ & 185.23 & 147.22 & 118.25 & 137.61 & $\begin{array}{l}\mathrm{AC}(p \leq 0.007) \\
\mathrm{AB}(p \leq 0.05)\end{array}$ \\
\hline & $\pm \mathrm{SD}$ & 26.59 & 6.89 & 23.11 & 26.26 & $\mathrm{AD}(p \leq 0.05)$ \\
\hline
\end{tabular}

$\bar{x}$ - mean; $\pm \mathrm{SD}$ - standard deviation

UA concentration was at its highest 4 weeks before delivery and differed significantly from the remaining data of analysis (Table 3 ).

Moreover a positive correlation $(p \leq 0.05)$ between Ino and Hyp concentration was found in goats one week before delivery $(r=0.99), 2$ and 3 weeks after delivery $(r=0.80$ and $\mathrm{r}=0.82$, respectively) and negative correlation between Hyp and UA in goats 4 weeks before delivery $(r=-0.88)$ and 3 weeks after delivery $(r=-0.92)$.

\section{Discussion}

Purine metabolism involves synthesis and degradation of adenine nucleotides, and determines the adenylate pool value. In this way, it is responsible for the absolute value of intracellular ATP concentrations. The unique erythrocyte structure and metabolism is due to, among others, a deficiency of glutamine 5'-phosphoribosyl 1-pyrophosphate (PRPP) amidotransferase (EC 2.4.2.14) and its inability to synthesize adenine nucleotides in the de novo pathway. Thus, in erythrocytes these compounds are formed in the reactions of reutilization, i.e. the reutilization of free purine bases (adenine and hypoxanthine) and nucleosides (adenosine and inosine). The reutilization of adenine nucleosides and bases is a source of erythrocyte purine mononucleotides (AMP). The metabolic aim of these reactions is the introduction of these compounds into the high energy purine nucleotide synthesis pathways (ATP, ADP) (Dudzinska et al. 2006).

During the periparturient period an oxygen and energy demand is increased, therefore a pregnant female is particularly exposed to energy imbalance especially due to catabolism 
changes as well as imbalance of prooxidant-antioxidant processes. The catabolic processes are intensified in conditions of hypoxia causing increased degradation of adenylate metabolites.

In our study ATP concentration in blood of the examined goats was constant during the periparturient period, but ADP and AMP concentrations changed and reached the peak one week before delivery, which indicates to the intensified degradation of adenylate increase in this period. The relation between ATP, ADP and AMP concentration determines the value of adenylate energy charge (AEC), which in physiological conditions is always 0.8 0.9 (Dudzińska et al. 2006). The results obtained are in accordance with the expected ones: AEC value in all the examined groups was approximately constant and ranged $0.82-$ 0.86 (Table 1). The lowest AEC value was found in goats 1 week before delivery and significantly different with the value obtained in goats 3 weeks after delivery. The lowest AEC value (within the physiological range) indicates an increase in changes of metabolic pathways. This leads to the simultaneous degradation of adenine nucleotides and intensified compensation of changes by the increased adenine reutilisation which leads to intensified ATP resynthesis (Słomińska et al. 2001). Lack of ATP concentration changes during the periparturient period in the examined goats represents favourable changes which lead to the adaptation of red blood cell metabolism to the growing oxygen demands during the delivery effort. It indicates high capability for homeostasis maintenance and high adaptive efficiency of the red blood cell system and whole organism to delivery, which is an enormous strain for the pregnant female.

One week before and two weeks after delivery we observed a significant increase in SOD and $\mathrm{GR}$ activities and an increase in $\mathrm{NAD}^{+}$and $\mathrm{NADP}^{+}$concentrations but a significant decrease in Hyp and UA concentrations

Similar tendencies in SOD and GR activities were observed in the periparturient period in cows and mares (Górecka et al. 2002; Markiewicz et al. 2005). An increase in SOD activity before and just after delivery is potentially a response to the increased production of reactive oxygen species ROS, which is generated in large amounts during haemoglobin oxidation (Markiewicz et al. 2005). Reactive oxygen species are the products of molecular oxygen metabolism, oxygen being in a triplet state $\left({ }^{3} \mathrm{O}_{2}\right)$. The triplet state of oxygen limits the two-electron reactions speed, resulting in the molecule being a weak oxidant. Molecule ${ }^{3} \mathrm{O}_{2}$ reacts with many compounds in one-electron reduction reaction, creating a superoxide anion-radical $\left(\mathrm{O}_{2}^{\bullet}\right)$ or superoxide radical - a protonized form $\left(\mathrm{HO}_{2}\right)$ in water medium. The production of superoxide anion-radicals is in part caused by reactions catalyzed by NAD $(\mathrm{P}) \mathrm{H}$ oxidases and xantine oxidase (EC 1.17.3.2) (Dröge 2002).

Superoxide anion-radical shows high reactivity when in the presence of compounds containing thiolic groups (-SH). It also reacts with reducing compounds, e.g., with ascorbate or $\mathrm{NADH}$, and may initiate lipid peroxidation. When in the presence of metal ions with varying valence it also exhibits a high reactivity level (e.g. it reduces $\mathrm{Fe}^{+3}$ to $\mathrm{Fe}^{+2}$ ions) - an important processes for erythrocyte metabolism (Dröge 2002; Markiewicz et al. 2005).

As a result of dismutation of superoxide anion-radical $\left(\mathrm{O}_{2}^{\circ}\right)$ there is an increase in the quantity of hydrogen peroxide produced, a reaction catalyzed by superoxide dismutase as a product of dismutation of two superoxide anion-radicals (Halliwell and Gutteridge 1999). An increase in the quantity of intracellular hydrogen peroxide enhances an increase in GPx (and CAT) and subsequently GR activities. GR is responsible for the regeneration of a reduced glutathione level, and its activity influences the activity of glutathione peroxidase (Janiak et al. 2010). One can speculate that the increase in the activity of enzymes observed in this research was a result of the described mechanism.

$\mathrm{NAD}^{+}$and $\mathrm{NADP}^{+}$play an important role as nicotinamide coenzymes of dehydrases, enabling a free intracellular transfer of reducing equivalents. This reaction type, in which 
one substrate is oxidized at the expense of another, is useful especially in the absence of oxygen, and enables the oxidoreductive processes (e.g., anaerobic glycolysis in erythrocytes). $\mathrm{NADP}^{+}$plays an important role as a coenzyme of dehydrases of the pentosephosphate pathway, contributing to NADPH production, which in turn influences GR activity. An increase in concentrations of $\mathrm{NAD}^{+}$and $\mathrm{NADP}^{+}$was observed in this research and shows an increase in oxygen consumption and intensification of energy-conversions in pregnant females, both before and after delivery. It also seems that the increase of glucose changes in blood cell takes place during a pentosephosphate pathway with simultaneous restrictions of its metabolism during anaerobic glycolysis changes (Wójcicka et al. 1977; Poręba and Pedzikiewicz 1996; Skotnicka et al. 2008). It is in accordance with the fact that during physiological pregnancy an increase of $\mathrm{pO}_{2}$ and a simultaneous decrease of $\mathrm{pCO}_{2}$ in blood is found. It is determined by increasing progesterone concentration of the respiratory system stimulator. According to the literature physiological pregnancy leads to the increase of $\mathrm{NADP}^{+}, 2,3-\mathrm{BPG}$ and total amount of phosphates in the erythrocytes.

Moreover, the research results of pregnancy physiology show that the amount of anaerobic glucose change coenzyme: $\mathrm{NAD}^{+}$in pregnant women does not change compared to nonpregnant women (Poręba and Pedzikiewicz 1996), whereas NADP ${ }^{+}$concentration increases (pentose pathway coenzyme) (Wójcicka et al. 1977).

An increase in ADP, AMP, Ino and Hyp concentration in the periparturient period shows an increase in the body's energy demand and the exacerbation of adenine nucleotides catabolism (Tavazzi et al. 2000). It is widely accepted that uric acid is the main extraenzymatic lowmolecular blood antioxidant, both intra- and extra-cellular. The antioxidative mechanism of uric acid activity has not been entirely defined and its protective activity is associated with the production of stable complexes with iron and copper ions and with ascorbate protection (Yo 1994). A decrease in UA concentration of goats in the periparturient period shows the small proantioxidant role of UA in goats in this cycle. In mares and cows, the part UA plays in this regard is more pronounced (Górecka et al. 2002; Markiewicz et al. 2005).

Catabolic processes increase especially in the conditions of hypoxia, which is shown by the disturbance of adenine metabolism and the generation of reactive oxygen species (ROS) with the use of xanthine oxidoreductase the substrates of which are hypoxanthine and xanthine accumulated in tissues and created during the intensive ATP catabolism (Tavazzi et al. 2000). Considerable decrease of ATP concentration in red blood cells is the consequence of hydrogen ion concentration increase, which results both in a lower 2,3BPG concentration in blood cells and lower activity of glycolytic cycle enzymes, especially hexokinase activity, phosphofructokinase and pyruvate kinase (Bontemps et al. 1986; Mateos et al. 1989). The decrease of ATP concentration in red blood cells is connected with the state of newborn, whereas the ATP concentration may by an indicator of chronic intrauterine foetus hypoxia (Mateos et al. 1989).

Uric acid and total oxypurines ratio decreases in the conditions of hypoxia (Tan et al. 1993). Moreover, the ratio of uric acid concentration to total oxypurines in a pregnant woman with hypertension induced by pregnancy is lower and hypoxanthine concentration is higher compared to physiological pregnancy (Klejewski et al. 2000; Bainbridge and Roberts 2008). This indicates intensified purine nucleotide degradation and reduced hypoxanthine reutilisation in pathological pregnancies and in hypoxia. In the conditions of cell energy crisis the increase of uric acid concentration and increase of free oxygen radicals can be observed. There is a higher demand for enzymatic as well as nonenzymatic antioxidants, e.g. uric acid which is also considered a cell energy state indicator. The uric acid inhibits the xanthine dehydrogenase activity which results in an increase of hypoxanthine concentration - lowered cell ATP concentration marker (Klejewski 2000).

The changes in hypoxanthine concentration found in our research and its decrease 1 week 
before and 2 weeks after delivery indicate a balance between resynthesis processes and adenine nucleotide degradation. It is also confirmed by the results of adenylate metabolite concentration results, especially AEC concentration in the examined goats. It confirms that high energy purine metabolites of the erythrocytes in the periparturient period undergo adaptive changes which are to equalize oxygen and energy lacks. The maintenance of prooxidative homeostasis in blood also changes.

Our results indicate the deterioration of antioxidative defense in the periparturient mechanisms of goats with the simultaneous maintained efficiency of adaptive processes shown by an increase in enzyme antioxidative activity. The dynamics and direction of the observed changes show that the maintenance of the proantioxidative homeostasis in goats depends mainly on enzymatic mechanisms.

\section{References}

Arikan S, Konukoglu D, Arikan C, Akcay T, Davas I 2001: Lipid peroxidation and antioxidant status in maternal and cord blood. Ginecol Obstet Invest 51: 145-149

Braci R, Perrone S, Buonocore G 2002: Oxidant injury in neonatal erythrocytes during the perinatal period. Acta Pediat Suppl 91: 130-134

Dröge W 2002: Free radicals in the physiological control of cell function. Physiol Rev 82: 47-95

Bainbridge SA, Roberts JM 2008: Uric acid as a pathogenic factor in preeclampsia. Placenta 29 Suppl A: 67-72

Bontemps F, Van den Berghe G, Hers HG 1986: Pathway of adenine nucleotide catabolism in erythrocytes. J Clin Invest 77: 824-830

Dudzinska W, Hlynczak AJ, Skotnicka E, Suska M 2006: The purine metabolism of human erythrocytes. Bochemistry 71: 467-475

Erisir M, Benzer F, Kandemir FM 2009: Changes in the rate of lipid peroxidation in plasma and selected blood antioxidants before and during pregnancy in ewes. Acta Vet Brno 78: 237-242

Gitto E, Reiter RJ, Karbownik M, Tan DX, Gitto P, Barberi S, Barberi I 2002 Causes of oxidative stress in the pre- and perinatal period. Biol Neonate 81: 146-157

Górecka R, Kleczkowski M, Klucinski W, Kasztelan R, Sitarska E 2002: Changes in antioxidant components in blood of mares during pregnancy and after foalin. Bull Vet Inst Pulawy 46: 301-305

Halliwell B, Gutteridge JMC 1999: Free Radicals in Biology and Medicine. Oxford University Press, Oxford, New York

Janiak M, Suska M, Dudzinska W, Skotnicka E 2010: Blood glutathione status and activity of glutathionemetabolizing antioxidant enzymes in erythrocytes of young trotters in basic training. J Anim Physiol Anim Nutrit 94: 137-145

Klejewski A, Szczesniak-Klejewska A, Zeromska-Cancellaro M, Urbaniak M 2000: Plasma purine turnover metabolites in women with normal pregnancy and pregnancy complicated with induced hypertension as compared to fetal well-being indices. J Perinat Med 28: 339-406

Makker A, Bansode Fw, Srivastava Vm, Singh MM 2006: Antioxidant defense system during endometrial receptivity in the guinea pig: effect of ormeloxifene, a selective estrogen receptor modulator. $\mathrm{J}$ Endocrinol 188: $121-134$

Markiewicz H, Gehree M, Malinowski E, Kaczmarowski M 2005: Antioxidative potential in the blood of perinatal cows (in Polish), Med Wet 61: 1382-1384

Mateos FA, Puig JG, Ramos TH, Carranza RH, Miranda ME, Gasalla RC 1989: Erythrocyte ATP (iATP) as an indicator of neonatal hypoxia. Adv Exp Med Biol 253: 345-352

Poreba R, Pedzikiewicz J 1996: The influence of kinetic stimulation of pregnant women on hematological indicator and erythrocytes adenine nucleotides concentration. (in Polish) Post Rehabilit 10: 41-46

Sies H 1997: Oxidative stress: oxidants and antioxidants. Exp Physiol 2: 291-295

Skotnicka E 2003: Circadian variations of the plasma renin activity (PRA), aldosterone and electrolyte concentrations in blood plasma in pregnant and non-pregnant goats. Comp Bioch Physiol 134: 385-395

Skotnicka E 2005: Diurnal changes of plasma arginine-vasopressin concentration in pregnant and non-pregnant goats (Capra hircus). Acta Vet Brno 74: 43-49

Skotnicka E, Baranowska-Bosiacka I, Dudzińska W, Suska M, Nowak R, Krupecki K, Hłynczak AJ 2008: The effect of exhaustive exercise on the concentration of purine nucleotides and their metabolites in erythrocytes. Biol Sport 25: $35-55$

Słomińska E, Szolkiewicz M, Rutkowski B, Swierczynski J 2001: Adenine reutilization as a cause of the increased ATP concentration in the erythrocytes of patients with chronic renal failure. (in Polish) Pol Arch Med Wew 105: $45-50$

Smolenski RT, Lachno DR, Ledingham SJM, Yacoub MH 1990: Determination of sixteen nucleotides, nucleosides and bases using high-performance liquid chromatography and its application to the study of purine metabolism in hearts for transplantation. J Chromat Sci 527: 414-420 
Szelachowska M, Abdelrazek S, Zonenberg A, Kinalska I 2002: The role of oxidative stress in pathogenic processes. (in Polish) Terapia 5: 1-7

Tan S, Radi R, Gaudier F, Evans RA, Rivera A, Kirk KA, Parks DA 1993: Physiological levels of uric acid inhibit xantine oxidase in human plasma. Pediatr Res 34: 3-8

Tavazzi B, Di Pierro D, Amorini AM, Fazzina G, Tuttobene M, Giardina B, Lazzarino G 2000: Energy metabolism and lipid peroxidation of human erythrocytes as a function of increased oxidative stress. Eur J Biochem 267: 684-689

Toescu V, Nuttall S, Martin U, Kendall MJ, Dunne F 2002: Oxidative stress and normal pregnancy. Clin Endocrin 57: 609-613

Upadhyaya C, Mishra S, Singh PP, Sharma P 2005: Antioxidant status and peroxidative stress in mother and newborn - a pilot study. Indian J Clin Bioch 20: 30-34

Wender-Ożegowska E, Kozlik J, Ozegowski S 2004: Changes of oxidative stress parameters in diabetic pregnancy. Free Radic Res 38: 795-803

Wójcicka J, Roszkowski I, Janczewska E 1977: Adenine nucleotides, coenzymes and intermediate glycolysis metabolites in red cells of pregnant women in normal gestation and in cases of diabetes mellitus. (in Polish) Gin Pol 48: 761-776

Yo BY 1994: Cellular defenses against damage from reactive oxygen species. Physiol Rev 74: 139-162 